\title{
IMPROVING THE QUALITY OF
}

\section{Telephone Reference Service}

\section{Brian Quinn}

\section{INTRODUCTION}

Although the telephone constitutes an important aspect of reference service in many libraries, it is frequently taken for granted or overlooked by both patrons and professional staff alike. Often, it is seen by librarians as merely an adjunct service, or even something of a nuisance. In this view, telephone reference is considered secondary and subordinate to serving on-site patrons.

Yet it can be argued that the quality of telephone reference service is of vital importance to the library, because it conveys an image of the library to patrons and to the larger community. Telephone reference can be utilized as a form of outreach to nonusers and can help expand the visibility and value of the library to the community.'

A well-run telephone reference program can also benefit the library by allowing staff to collect data about the service needs of various parts of the community. By keeping a log of the kinds of questions asked by callers, the library can get a better sense of how to meet the information needs of its users. ${ }^{2}$ The volume of calls received can also be a gauge of the success of various promotional efforts undertaken by the library.

Many of the studies conducted to date have focused on telephone reference service in public libraries. Telephone reference seems to be deliberately underpromoted in some academic libraries; calls are

Quinn is social sciences librarian, Texas Tech University Libraries, Lubbock, Texas. neither encouraged nor discouraged. This may be the result of a belief of some academic librarians that their 
mission is primarily one of instruction rather than the provision of information. It is thus preferable for students to obtain their information firsthand by coming to the library, where they can be instructed in how to find information rather than simply providing it to them over the telephone. These librarians believe telephone reference does not adequately afford the academic librarian the opportunity to teach users how to use the library. ${ }^{3}$

This belief may change as the quality of telephone reference becomes increasingly important due to emerging technologies that are becoming increasingly prevalent on many campuses. Dial-in access via personal computer and modem now enables many students to search library catalogs and other databases remotely. It is no longer uncommon to have students calling the reference desk from home with questions concerning the material they have found online. In addition, some patrons may prefer to communicate their queries via e-mail. Now that both patron and librarian have electronic access to the same reference sources, the telephone reference inquiry may gradually come to resemble the traditional face-to-face interview. ${ }^{4}$

\section{Characteristics of Quality Phone Reference}

Librarians tend to equate quality telephone reference service with the accuracy of the answers provided. But accuracy is only one of several factors that constitute quality telephone reference work. Other aspects of service that can contribute to the overall quality of telephone reference include speed, etiquette, versatility (the ability to juggle telephone questions and on site patron requests simultaneously), and promotion.

\section{Speed}

Speed is an important factor in any telephone reference transaction, if only because callers don't like to be kept waiting. Callers may not realize that it can take a few minutes for the librarian to formulate a search strategy, and several additional minutes for the appropriate sources to be consulted. Some callers may simply expect the librarian to know the answer immediately. The time it takes for a librarian to respond may seem even longer to a patron who has been put on hold, and cannot actually see the librarian carrying out the search.

\section{Etiquette}

Etiquette becomes a significant consideration when one realizes that even an accurate, prompt answer may not compensate for being treated in a rude, gruff, or indifferent manner. Because the caller has no visual cues to go by, the librarian's tone of voice and overall manner may take on heightened significance. Even a simple gesture, such as periodically reassuring the caller that the librarian is still searching for an answer and has not forgotten the caller, can be extremely important to a patron. Or, if the caller has been on hold while the librarian is away from the desk, it may help to reward the caller's patience by saying "Thanks for waiting."

\section{Versatility}

Another important aspect in considering the quality of telephone reference work is the versatility of the librarian. The telephone may ring in the midst of answering another patron's (or another caller's) question. The librarian must then face the problem of how to handle the two requests simultaneously. A quick assessment of the difficulty of the two questions, and probable length of time and effort required to answer them may be necessary. Skill and tact on the librarian's part is required in order to keep each patron from feeling slighted or neglected.

\section{Promotion}

A crucial factor in determining the overall quality of telephone reference service is how well the service is publicized and promoted. No service, regardless of its overall quality, can be considered effective unless people know about it and use it. The American Library Association(ALA) recognized this in the early eighties and launched a national campaign to promote telephone reference service. Known as the "Call Your Library" campaign, it included television, radio, and print ads to raise public awareness of this important service. ${ }^{5}$ Another campaign sponsored by New York City libraries featured the use of wallet-size cards inscribed with the message "Call the Library for Fast Facts."

\section{Policies ANd Guidelines for Quality SERvice}

Libraries and professional library organizations have recognized the importance of quality telephone reference service and have attempted to develop specific guidelines for telephone reference work. In its guidelines for medical, legal, and business responses, the Reference and Adult Services Division of the ALA points out how easy it is to misinterpret telephone messages, and recommends that special care be taken in answering them. In order to prevent malpractice claims, the guidelines suggest only factual information be given out over the telephone. The guidelines also 
suggest that brief information should be read verbatim without the librarian offering any interpretation of it, and that the source of information always be provided. In some cases, it may be necessary to inform users that, although the library possesses the information, the caller will have to come to the library to use it. ${ }^{7}$

One example of a library that has developed its own telephone reference guidelines is the Alfred Taubman Medical Library of the University of Michigan. Included in its guidelines are provisions for providing telephone reference service during busy periods (on-site requests are given priority over telephone calls). Another issue covered is how to handle a large volume of requests for verification of citations and holdings information. The librarian is advised to "make a reasonable judgement" and "offer a positive alternative" beyond what can be immediately accomplished. If an on-site problem requires the librarian to be away from the desk, another librarian should be asked to assist the caller, or an appointment made to continue with the problem later. ${ }^{8}$

Establishing policy guidelines for quality service is important because it helps to define what quality is. One policy consideration that needs to be decided in advance, for instance, includes the length of time that should be spent answering a question (often three to five minutes) before either referring the patron to another desk or agency or asking the patron to come in to the library to continue his or her research. Another issue is how homework inquiries, contest questions, medical/legal information, and criss-cross directory questions are to be handled.

\section{Evaluating Telephone Reference: A SURVEY OF THE LITERATURE}

Determining how well telephone reference service is currently being performed in libraries is difficult, because the available evidence in the literature is somewhat sketchy. While a number of articles have been written on the topic of telephone reference service, only some report on how well the service is actually performed. In many of these studies, quality is equated solely with accuracy, while factors such as speed, etiquette, or versatility are ignored.

One of the earliest studies was completed in 1980 by Marcia Myers. ${ }^{9}$ She selected a random sample of 40 libraries in nine southeastern states. Each library was asked 12 factual questions via telephone, and the percentage of correct responses was recorded. Results indicated that the libraries sampled answered from 25 to 75 percent of the 12 queries correctly. No library staff answered all 12 correctly. Performance was poorest on questions that could not be readily answered with the standard set of basic reference tools. Overall, only about 50 percent of the test questions were answered correctly.

Myers' findings also indicated that even when the library owned the appropriate source, the staff member often failed to consult it, did not know how to use it, or misinterpreted the information obtained from the source. Library staff also frequently failed to identify to the caller the sources consulted.

When Myers further analyzed the findings by type of institution, she found significant differences in the accuracy of the responses. The average number of correct responses progressively increased from two-year colleges to four-year colleges, followed by four-year colleges with graduate programs, with universities receiving the highest score of correct responses. The author attributed the differences in accuracy to the fact that the larger institutions have larger collections that the staff are better able to exploit. She concluded by suggesting that telephone reference service needs to be improved and that more attention should be paid to quantitative factors such as hours of service and number of volumes held.

Another early study was done in 1980 by Mary Lee Bundy ${ }^{10}$ and her colleagues. They surveyed nine public libraries by posing as patrons and calling the library with questions. Seven questions were asked, with the responses then recorded and analyzed. The questions were basic factual ones that could be easily answered by consulting ready reference sources or by referring the caller to an appropriate agency or organization.

The results of the study indicated that almost half the responses were incorrect. In several instances, librarians gave the caller information that did not answer the question, or told the caller that they had no materials in the library related to the question (subsequent checking by the researchers revealed that they did). In other instances, libraries supplied the caller with wrong information or made vague or dubious referrals. Perhaps most telling, the researchers noted that the responses to questions indicated both a lack of interest in the subject and a lack of concern for the caller's information need. Variables like apathy are seldom measured in studies of telephone reference, but they have a serious effect on the quality of service.

Bundy and her colleagues pointed out that in several cases, the service they received seemed hurried, and was obviously being delivered by an overburdened staff. They dubbed this approach to telephone reference service the "quick and dirty" approach. It is characterized by a lack of time given to thoughtful consideration of the question, and replying with the first answer that comes to the librarian's mind. 
Other deviations from quality service included the failure of librarians to ask questions of the patrons to find out what they really needed; a reliance on memory for answers rather than checking the actual sources (which resulted in wrong answers); failure to cite the source of the information to callers; failure to check or use sources available in the library; misuse of standard reference tools resulting in incorrect answers or referrals; an inability to spend adequate time with a caller; and a failure to follow through to see if the callers' questions were answered satisfactorily.

In 1981, Diane M. Brown analyzed telephone questions at the Chattanooga-Hamilton (Tennessee) Public Library by subject, answer format, and level of complexity. " Sixty-six percent of the 648 telephone calls analyzed were found to be informational, with only 34 percent considered reference. Few calls could be characterized as complex, because only nine percent of all calls required searches beyond the ready reference collection. The author concluded that most telephone patrons need short factual answers that could be provided by well-trained paraprofessionals. It should be noted that although Brown reported that 70 percent of all reference questions were answered, and a partial answer or referral was made for another 19 percent, no attempt was made to determine the accuracy of the answers. Other variables affecting the quality of telephone reference service such as speed or etiquette were also not considered.

Sharon L. Bostick wrote an article in 1986 on her experience managing the Oakland County (California) Reference Hotline. ${ }^{12}$ The program is unusual in that it is based at Oakland University but provides reference services for 38 public libraries. Public librarians can call the hotline with questions after they have exhausted their own libraries' resources.

If the hotline is unable to answer the question, they will try to refer callers to another library. The hotline has been able to answer 60 to 80 percent of the reference requests, with the average response time being three hours. One difficulty that the hotline staff report is that they never have the opportunity to speak directly with a patron. The article suggests that working through a middle person can tend to cause communication difficulties.

In 1987, a study of telephone reference service was conducted at the Fairfax County (Virginia) Public Library (FCPL) system by Eleanor Jo Rodger and Jane Goodwin. ${ }^{13}$ A small number of staff acted as callers to various branch libraries, and each library was asked a total of 25 questions. The questions asked consisted of 15 ready reference questions, five in-system referrals, and five that required some negotiating.

Three-hundred fifty FCPL responses were analyzed for both accuracy and etiquette. Regarding accuracy, it was found that staff do very well answering direct, factual, ready reference type questions. The staff did less well with more complex questions that needed negotiation to determine the information the callers really wanted. When a caller would ask a general question, staff members failed to probe for what specific data the caller was seeking.

Staff were also faulted for answering most of the questions about FCPL resources and services incorrectly or incompletely. When asked if the library owned certain books or films, staff would answer simply "yes" or "no," without giving further information about the item sought or a referral. Again, poor interviewing skills were the reason.

The study also measured the etiquette or ambiance involved in the reference transaction. Callers were asked to rate the librarians on how easy they were to understand, how attentive they were to their questions, and the overall tone and manner of the persons answering the calls. It was found that 89 percent of the time, staff members were easy to understand, 82 percent of the time they gave a high level of attention to questions, and 86 percent of the time they were professional and courteous in manner.

In response to the findings, FCPL staff developed a short, easy-to-use booklet of facts about services and resources offered. The library also acquired a training video for use in a refresher course on how to conduct a complete reference interview. A study guide was also prepared to accompany the video. The guide emphasizes points like closing the reference interview by asking if the patron's needs have been met, and the need to speak slowly and clearly as patrons are writing down information being conveyed over the telephone.

In 1988, another study of telephone reference service was conducted at the Central Massachusetts Regional Library System in Worcester. ${ }^{14}$ Twenty-four of 70 member libraries participated in the study, which was done by Jane Goodwin, a consultant. By telephone, proxies asked questions that were designed to assess ready reference.

The results of the study indicated that callers received correct responses to their questions approximately 50 percent of the time. The most accurate answers were given in response to ready reference questions. Librarians tended to handle medical, legal, and consumer queries less well. The least accurate responses were given to questions that necessitated the use of an online database.

A third study published in 1988 by W.W. Scott focused on academic libraries. ${ }^{15} \mathrm{He}$ surveyed $96 \mathrm{ACRL}$ member libraries to determine whether and to what degree these libraries offered telephone reference service. Although he did not specifically ask questions about the accuracy of telephone reference service, he 
did ask what efforts the library made to serve the public more effectively. Seventy-nine of the 89 libraries providing telephone reference service had set up specific communication channels whereby questions that could not be answered by clerical or paraprofessional staff were referred to professional librarians.

Questions that required more in-depth research than "ready reference" were handled in one of several ways. Fifty of the libraries indicated that a telephone number was requested from a student and a return call made to provide the requested information. Twenty-two of the libraries responded that they would request that the student come to the library for further assistance. Several other libraries said their response would depend on how busy they were at a given time.

The responding libraries indicated that they provide telephone reference service regardless of whether a question is related to a class assignment. Sixty-eight libraries responded that they would not answer a student's question over the telephone if they thought the student would benefit by using a given reference source, or if the length of the request suggested that there was an assignment involved that the student should be doing alone.

Since only five of the libraries surveyed had separate telephone desks, respondents were asked to what extent they believed telephone reference interfered with service to on-site patrons. Sixty-nine respondents felt that telephone reference service had posed no problem or hindrance to working at the desk. Sixteen of the 20 libraries that felt it did pose difficulties stated that the problem stemmed from calls received during peak periods of activity at the reference desk, or when the reference department was short-staffed. Respondents mentioned setting priorities in the form of written guidelines as a possible solution.

Another study that focused on academic libraries, particularly health sciences and hospital libraries, was conducted by Beth M. Paskoff in 1991. ${ }^{16}$ Researchers telephoned 51 libraries and unobtrusively asked six questions to determine the accuracy of telephone reference service. A total of 306 queries were asked.

Sixty-three percent of these were answered accurately. Four libraries provided complete and accurate answers to all six queries, and 78 percent provided information that was not complete but nevertheless not inaccurate. No library answered more than one query inaccurately.

In contrast to Myers' study, no significant correlations were found between the accuracy of the answers given and the size of the collection or number of staff. Libraries with larger operating budgets did tend to provide more accurate answers. Another significant variable was the presence of at least one person on the staff who had a master's degree in library and information science.

Of the 11 inaccurate answers given by respondents, two were cases of misspelled words. In two other cases the librarian misunderstood the questions and proceeded to locate the wrong information. The other seven inaccurate answers were attributed to the librarians' inattention to specific information that was requested in the query.

Twenty-five percent of the queries resulted in referrals to other libraries or institutions. Seven percent of the queries were not answered, largely because the libraries did not answer queries from the public. Three of the "no answer" responses resulted when the library said it did not have the needed source, and in another eight the librarian stated the sources were available but failed to provide the answer.

In 1991, Tammy Nickelson Dearie and Alice J. Perez conducted a survey to determine how well telephone reference service at the University of California, San Diego's (UCSD) Central Library was meeting the needs of their primary patrons. ${ }^{17}$ Telephone access had become more difficult for primary patrons (faculty, staff, and students) in recent years as a result of an increasing volume of requests from patrons, both onsite and via telephone. The library had established an information services desk to screen incoming calls. A staff of paraprofessionals handled directional, holdings, and basic informational calls, and transferred reference calls to the reference desk. If the librarians at the reference desk were preoccupied and could not answer the telephone, the call would automatically transfer to an answering machine, which would inform the caller that the reference desk was busy.

Even with the information desk screening calls, the reference department was concerned that many calls were going unanswered. The results of the survey indicated that of the 616 calls received at the information desk during the survey, 176 of those forwarded to the reference desk went unanswered. Fifty-nine of these calls were from UCSD patrons, the library's primary clientele.

In order to reduce the number of unanswered calls, the library decided to investigate several options. Possibilities discussed included establishing a separate telephone reference department and purchasing an automatic call sequencer, which answers calls and places callers on hold. A third possibility discussed involved an e-mail reference service that would allow UCSD patrons to query reference librarians electronically via the campus computer system.

Another study done in 1991 by Frank R. Allen and Rita H. Smith at the University of Tennessee at Knoxville involved a similar problem. ${ }^{18}$ The library's reference department was being overwhelmed by an 
increasing volume of calls, and could no longer respond adequately. The library decided to conduct a survey designed to count and categorize the types of questions asked. The key question that the researchers sought to answer was how the library could be better organized to handle the volume of telephone calls.

Of the 1,630 calls received during the survey period, 33 percent could be categorized as reference and another nine percent as CD-ROM signups or holdings calls. The remaining 56 percent of calls included transfer calls, library hours calls, and library policy calls. This last group of calls could be handled by nonprofessionals. As part of the survey, it was determined that student assistants needed no help with 94 percent of the questions asked, further suggesting that this might be a possible solution.

The survey concluded that the reference department was receiving a significant number of nonreference calls. The researcher recommended that the library establish a separate information number with a separate staff to operate it. The staff could be made up of welltrained student assistants, especially on nights and weekends when calls were fewer and professional librarians less available.

The most recent study of telephone reference, done by Deborah C. Duke, focuses on the Night Owl Telephone Reference Service at the Enoch Pratt Free Library in Baltimore. ${ }^{19}$ The telephone service staff keep detailed records of all calls, allowing the author to track its performance. Staff members record the time of each call, the question, the answer, and whether (in their opinion) the question was answered completely and correctly, or not at all, or whether it was beyond the scope of the service.

Records indicated that the service received an average of 59 calls per night, with an 83 percent overall completion rate. If this success rate seems unusually high, it should be remembered that staff members rated themselves. Up to 500 calls a month were lost to busy signals, which resulted in an additional librarian being added and a third line being opened up.

Approximately 96 percent of the questions received were ready reference. Staff report being able to answer 84 percent of these, and partially answer another 10 percent. "Partial" answers involve referrals to other institutions, the provision of at least some of the information requested, and requests for materials from other libraries. Librarians report they were unable to find answers for six percent of the questions. The average length of a call is seven minutes, but staff sometimes exceed the limit if it is needed to do a thorough search.

Staff members conduct an annual survey of callers to find out why they use the service, how they heard about it, how often they utilize it, and how satisfied they are with it. Each year over 95 percent of callers report that they are "very satisfied" with the service. Even in those instances in which patrons' calls were unanswered, they said they were still satisfied with the service and glad it was available at the late hours. The results of this study need to be taken with some caution, since callers may not really know if they are getting quality service or not.

Overall, the portrait of telephone reference service that emerges from these studies is not a flattering one. Even if quality service is merely equated with accuracy, which it seems to be in many of these surveys, the accuracy rate seldom rises above 50 or 60 percent. However, as was pointed out earlier, accuracy is just one aspect of quality telephone reference service. Other factors like speed, etiquette, and promotion need to be considered as well, even though they have been neglected in most studies.

Clearly, a review of the literature demonstrates that there is much room for improvement in the quality of telephone reference service. The remedy for this situation may lie in two areas that may offer much promise. The first is training for telephone reference work, and the second is new advances in technology. Each of these areas will now be examined separately.

\section{Training for Telephone RefERENCE}

If little attention has been devoted in the literature to the quality of telephone reference service, even less has been written about training. Using the telephone as a reference tool is not even taught in most library school reference courses. Yet training constitutes a primary means by which better quality telephone reference service can be realized.

Many commercial databases have taken the lead in training staff for telephone reference work. This is because their financial success often depends on their ability to provide a strong technical support line to users of their databases. Many vendors offer rigorous training programs for their staff that often include hands-on practice sessions and apprenticeships before an employee is considered capable of answering tollfree help lines.

In the forefront of these companies is Mead Data Central, which operates a help desk that is open 24 hours a day, seven days a week. It employs 64 people full time to staff its help desk telephones. Staff members must first complete a period of training before being eligible to be "certified" in an area of expertise..$^{20}$

Some academic libraries are also using innovative approaches in training staff for telephone reference work. The University of Alaska at Fairbanks has a tollfree number statewide that is heavily used. It offers 
more than basic interview training to help staff be more sensitive and responsive to user needs. The program emphasizes cross-cultural training, so that staff can better handle any situations that might potentially arise when two individuals from different ethnic or racial cultures attempt to communicate. ${ }^{21}$

The literature reveals three basic approaches to training for telephone reference work currently used in libraries. The first approach, which has been utilized successfully at Queens Borough Public Library, in New York, conducts training on two levels. The primary level consists of basic training of new employees in ready reference service, utilizing and maintaining the collection, information and referral skills, and basic online searching techniques. The secondary level involves teaching advanced classes that focus on refining techniques of more seasoned telephone reference staff.

Training sessions on both levels utilize a combination of one-on-one coaching, hands-on experiential exercises, and group discussion. A case study approach that analyzes a staff member's approaches to actual questions can be used to teach search strategies. Particular attention must be paid to difficult queries for obscure data and unsuccessful search strategies. The telephone reference process is analyzed and suggestions are made for improvement, with the overall atmosphere being unpressured, nonjudgmental, supportive, and open.

During practice sessions, staff are instructed to not treat ready reference questions as routine and impersonal. Discovering the patron's real need, which may be different from the actual question asked, is emphasized. One technique used to accomplish this is to probe deeper by further interviewing. Another is active listening, the process of "reading" a caller by listening closely for tone of voice, pauses, nervousness, or hesitation. Librarians are taught to encourage the patron to talk about the request. They are also asked to practice using a friendly, nonjudgmental voice to establish trust and encourage repeat usage. ${ }^{22}$

The second basic approach to training librarians for telephone reference work has been used by Rochelle Yates of the Telephone Reference Division of Brooklyn Public Library. It entails the use of quizzes as learning aids. The quizzes consist of series of questions covering a broad spectrum of subjects that patrons might conceivably ask over the telephone. They serve as a means for the librarian to become familiar with the collection, or for more experienced librarians to refresh their skills.

The next phase of this approach focuses on having the trainer teach the librarian the mechanics and etiquette of operating the telephone. Mechanics training includes the procedures for putting people on hold, transferring calls, how to gauge time limits, and so on. Etiquette involves the proper greeting and sign off, as well as checking back intermittently as the search is proceeding so that callers don't feel that they've been forgotten or abandoned.

The third phase of this approach involves having the trainer answer a few calls while the trainee listens in on another receiver or speakerphone attachment. The trainer models the correct behavior for the trainee to observe. By modeling behavior, the trainer has the opportunity not only to project the proper tone and manner, but also to demonstrate sources and strategies not covered in the quizzes. After the trainer has done some modeling, the trainee is then asked to answer some calls, with the trainer listening in. Beyond looking for facility with telephone technology, the trainer pays particular attention to how well the trainee is able to conduct the reference interview and to clarify the caller's request.

Among the interviewing skills emphasized in this phase of the training are asking open-ended questions, listening without interrupting, narrowing or broadening questions as required, clarifying any patron uncertainties or vagueness about questions, repeating questions to the patron, checking spellings, and verifying if answers are sufficient. In addition, the trainer checks to see that the trainee conveys an overall manner that is empathetic, friendly, and helpful.

The fourth and final phase of this second approach involves the trainer and trainee teaming up to answer questions. The trainee not only learns which sources to consult first, but where to check for updates, how to handle problem calls, and, most significantly, the importance of cooperation. By teaching the trainee to consult with other librarians on a question, it demonstrates how the power of synergy and pooling of staff knowledge can benefit the caller. ${ }^{23}$

Some beginning librarians may feel that their reference background is being challenged by using quizzes during the initial phase of this approach. For those librarians, an alternate method of learning is needed. One way to help librarians learn the collection is to get them involved in collection development for telephone reference. Have them evaluate and weed the telephone reference collection, and scour various review journals for new acquisitions that appear useful. ${ }^{24}$

The third approach to training librarians for telephone reference service differs markedly from the two approaches just discussed. It was developed at Athens-Clarke County Library for training staff. The program begins by having each trainee survey every telephone reference source in the ready reference collection. For each source, the trainee is asked to compile three to five reference questions on $3^{\prime \prime} \times 5^{\prime \prime}$ notecards, and to put their initials on the back. 
The questions are collected by the trainer, and the group is split up into pairs. The questions are redistributed to the group members, and each pair then exchange questions and search for the answers using the collection. Care is taken so that no trainee receives questions which he or she submitted.

The next phase of training in this third approach involves role playing. Pairs of trainees pretend they are placing and receiving calls from each other. They are expected to simulate the entire transaction from greeting to close, even including digressions, complaints, and "small talk." Trainees are even required to deliberately improvise several situations that could result in potential conflicts between patron demands and departmental policies. They are encouraged periodically to pose questions to their partners in a calculatedly vague, incomplete, or misleading way.

As these improvisations are occurring, the supervisor circulates among the trainees, observing the interaction, pointing out weaknesses, and making suggestions for improvement. The simulated calls not only serve to teach trainees practical skills but also act as a great confidence builder for handling actual calls. Trainees learn not only how to devise search strategies, but how to handle patrons and defuse tensions as well..$^{25}$

Once trainees have received their basic instruction in telephone reference service, the challenge becomes how to improve skills. A continuing education program is often the answer. This includes promoting staff awareness of new reference tools by shelving them in a special section such as a new book shelf, as well as maintaining a list of important new reference works to consult. Difficult or unanswered questions should be written down and discussed later in staff meetings. New sources and strategies should also be discussed regularly as part of staff meetings. Workshops should be organized on interview skills, the latest reference sources, and new technology. Staff members themselves should be encouraged to lead these sessions as a way of keeping them interested and knowledgeable. ${ }^{26}$ Overall, this system has proven to be effective for both trainers and trainees at Athens-Clarke County Library.

\section{TECHNOLOGY FOR TELEPHONE REFERENCE}

Besides training, another factor that can make a significant difference in the quality of telephone reference is technology. Although many people think of telephone technology as elaborate, computerized systems, other aspects of technology can improve service as well. In determining the optimal technology for quality telephone reference service, the entire work environment must be considered.
One extremely useful device is a central information carousel or "wheel," on which the most important reference works can be kept. This device has proven to be extremely useful at the Enoch Pratt Free Library in Baltimore. The wheel should contain four to five shelves with a capacity for 400 or 500 core works. Books can be arranged by subject matter rather than call number, and spines may be color coded by subject. For the kind of time-sensitive transactions that characterize telephone reference, a device like a carousel can greatly speed location of key sources needed to answer ready reference questions. ${ }^{27}$ Also useful are bulletin boards (actual or electronic) to store community information, and moveable stands on which to store large dictionaries.

Indeed, the vast potential of electronic databases to support telephone reference seems largely untapped. For example, a gopher system could be created that includes a series of hierarchically arranged menus to display the most important and most frequently requested information first. Information on related topics could be displayed on subsequent menus. Such a system would allow much more information to be accessed more rapidly and much easier than it could be from a typical manual Rolodex file of cards. ${ }^{28}$ In addition, if files in a gopher or Web-based system were WAISindexed for quick retrieval based on specific words or phrases, retrieval of needed data would be quicker.

Another electronic resource that might prove useful in conjunction with telephone reference work is a hypercard-based system. Such a system typically contains a menu featuring icons that, when clicked on by a searcher, yield further information about related topics. The information is contained on a series of cards through which the searcher can navigate because the information is linked by the icons. Unlike gopher systems, a searcher can move back and forth between the links without having to remember where they were in a hierarchy of menus. A hypercard system also offers multiple access points to key access areas of interest, so that the user doesn't need to learn a hierarchy. It thus offers a faster, easier, and more flexible way of accessing information, which is a critical consideration in telephone reference work, where speed and ease of access are vital. ${ }^{29}$

A third technological possibility that might prove useful for telephone reference work is the construction of a World Wide Web Page. The World Wide Web uses hypertext links, in which highlighted words serve as links to other related documents. Currently, there is some published literature relating the Web to library systems. ${ }^{30}$ In addition, there are now several basic HTML (hypertext mark-up language) editors available for free downloading (http://gfecnet.gmi.edu/software/ softhtm.html). 
It is possible to construct a home page on the Web that serves as an entry point for links to other documents quickly. Such a page might prove useful to the librarian who provides telephone reference service.

It is also possible to create a call-in information library that is capable of playing dozens of recorded messages on a variety of topics. The system can serve as a 24-hour answer line for many of the most basic questions that are frequently asked by telephone patrons. Possible topics might include anything from library hours to instructions on how to search OPACs and CD-ROMs, how to log into OPACs from home, how to cite sources correctly, and even how to do basic library research. Subjects on which tapes are available can be listed in pamphlets and promoted in local media. ${ }^{31}$ This type of phone-in information service, if well publicized, can substantially reduce the volume of routine calls that would normally have to be handled by the reference staff.

Regarding changes in telephone technology itself, one that has received little attention but has great potential for telephone reference service is the cordless telephone. Because it gives the reference staff freedom to move around, librarians are no longer confined to the reference desk. They can take the telephone "on location" back into the stacks or to CD-ROMs or special collections.

The telephone reference process is accelerated because the librarian can provide the answer as soon as the source is located, rather than having to walk back to the reference desk. The cordless telephone makes it possible for the librarian to continue the reference interview while searching for sources away from the desk. The librarian also has the freedom to physically pass the telephone to another librarian when working with a patron, so that telephone patrons have a better chance of being helped rather than being put on hold or kept waiting. ${ }^{32}$

The use of cordless telephones is not without its drawbacks. Current cordless telephone technology offers a limited FM frequency transmission range, usually 150 to 200 feet. This is typically enough to allow movement in the reference desk area but not throughout the entire building. Metal book stacks and steel building beams can also interfere with cordless telephone reception.

Cellular telephones require fairly elaborate technology to operate. Broadcast and relay nodes need to be placed at central locations throughout the building, usually on the ceiling. The nodes transmit signals to the telephone, even if it is taken far from the reference desk. However, the transmission relay nodes are expensive to purchase and install, and there is the constant expense of monthly line charges as well as additional per minute charges. It is likely that more cordless or cellular telephones will be used for telephone reference work in the future, as cordless telephone technology continues to improve, and as cellular telephone technology decreases in cost. ${ }^{33}$

While cordless and cellular technology show promise, automated telephone systems offer the greatest potential for improving the quality of telephone reference service. Systems can be configured with features like an automatic call distribution system, which automatically routes calls to the staff telephone that has been idle the longest; and a display that informs staff how long a patron has been on hold. This gives the librarian the option of apologizing to a patron for a long wait.

Systems can be designed so that callers on hold will be interrupted with a brief message to assure them they have not been forgotten. The system can be programmed to play soothing background music while callers are on hold. Systems are available with a timer that spaces the calls far enough apart so that staff have adequate time to reshelve reference tools between calls. Many systems will automatically record statistics as well.

Sophisticated microcomputer-based voice messaging systems are available that have capabilities beyond those of the typical answering machine. They offer such options as forwarding received messages to other users, listing messages received, and tagging a call as urgent by means of a signal light or audible tone. They can also dial out to another extension to contact the person being called and delay delivery of a message until a time specified by the caller. ${ }^{34}$

Voice messaging systems can be purchased and installed by the buyer, without the need for a systems expert. They can also be operated on a single telephone line. Such systems are not only capable of providing a mailbox for callers, they also allow the creation of an electronic directory of names, addresses, and telephone numbers. This can be useful for information and referral questions, because the system allows the user to scroll forward or backward through records, like an electronic Rolodex.

Perhaps the most interesting feature of voice messaging technology is that it can be programmed to allow automated attendant call branching. This feature enables a user to create custom configurations that will alter message sequences when prompted by a caller pressing various touch tone keys. Using call branching, a caller can be instructed to press " 1 " to get the circulation desk or " 2 " to get reference. The system then selects the proper message sequence based on the caller's response, and can deliver a single message or a complex series of messages with further branching options based on responses received. Complex branching can backfire, however, because callers will not 
appreciate intricate branching schemes that force them to make numerous touch tone selections just to get a simple answer. ${ }^{35}$

Several companies have begun using automated information retrieval systems based on the telephone. DataTimes and Dow Jones Personal Publishing have developed a "fax back" system that allows a caller to have the full text of a document delivered to his or her desktop via fax within 24 hours. A caller can dial the company's number, select an item from a voice menu, and enter a fax number along with an accession number or bibliographic citation of the article. The article is then delivered to the customer's fax machine, in sometimes as little as a few hours. These systems are not only fast and efficient, but relatively inexpensive for the user, who is generally charged a fee of $\$ 20$ to $\$ 25^{36}$

\section{CONCLUSION}

The current state of telephone reference service can be characterized as one of neglect and underutilization. All too often, it is thought of as an adjunct service, performed in a "quick and dirty" manner, because it is seen as secondary in importance to the service provided to on-site patrons. It is thus not surprising that many surveys indicate telephone reference is not done very well. A similar neglect can be said to characterize training for telephone reference.

This state of affairs is unfortunate, because when used proactively the telephone can be a powerful reference tool indeed. Because it offers direct and immediate contact with human sources of information, it can yield more current unpublished data than online or CD-ROM sources, which rely on published information. It is often faster and more economical than these sources as well.

The key is to be able to use the telephone creatively in order to tap its vast potential. In its current state, "telephone reference" refers almost exclusively to the service provided to callers to answer their questions when they phone the library. Telephone reference service is thus merely reactive. It needs to be redefined as a proactive service.

If librarians were suddenly to begin to use the telephone aggressively to track down information, they might realize how effective it can be. When used skillfully, it has the ability to dissolve geographic boundaries while permitting an interactive form of telecommunications not possible with online or CDROM systems. Using the telephone, a librarian can probe for, clarify, and follow up on information in a unique way that no other technology can currently match. The Internet may someday rival the telephone as a communications medium, but it does not at this point offer the telephone's ease or convenience.

If the telephone offers such vast potential as a reference tool, the question arises as to why it is so underutilized. A principle reason may be reluctance on the part of reference managers and library administrators to allow reference departments to call long distance. Yet library administrators are often pleasantly surprised at the low monthly cost of long distance relative to the expense of online or print tools. ${ }^{37}$ If library administrators realized how many questions go unanswered each year as a result of reference staff being unable or reluctant to call long distance, their attitude might change.

There are ways to keep long distance costs down that many libraries may not have considered. One is the use of Wide Area Telecommunications Service (WATS) lines, which offer relatively affordable unlimited long distance telephone service. Public and academic libraries that are located near one another could further reduce the cost of WATS service by sharing a line. ${ }^{38}$

Even without a WATS line, many librarians could make much greater use of long distance telephone reference by taking advantage of toll-free numbers. These numbers can be used to obtain information on products, services, prices, and suppliers, as well as technical information. ${ }^{39}$ Many national service organizations and government agencies also have toll-free numbers. ${ }^{40}$ Numerous toll-free directories exist, and many more toll-free numbers can be found in standard reference sources like the Encyclopedia of Associations. AT\&T also has a toll-free directory available on the Internet, at http://att.net/dir 800 . One way to encourage greater use of toll-free numbers by reference staff is to make a list of them and place it next to the telephone at the reference desk. It would also make a good topic for discussion at the next reference staff meeting.

Beyond the economic issue is a broader issue of policy. To return to a point made earlier in this study, academic libraries generally stress the need for instruction over information. It is for this reason that academic librarians have, to some extent, ignored the enormous potential of the telephone as a reference tool.

\section{NOTES}

1. Sandy Carlson, "Quick! I Need an Answer Right Away," PNLA Quarterly 56 (Fall 1991): 41.

2. Richard J. Beebe, "The Community Access Library Line: Benefits of a Toll-Free 800 Telephone Line," The Reference Librarian 21 (1988): 68. 
3. W.W. Scott, "Telephone Reference Services in University Libraries: A Survey of Service to Students," paper presented at the Association of College and Research Libraries Session of the Annual Meeting of the Illinois Library Association (11-13 May 1988): 6.

4. Edward A. Reidinger, "Telephone Information Service," College and Research Libraries News 50:8(1989): 672.

5. "Telephone Reference Promoted in National Campaign," Library Journal 106 (1 March 1981): 492.

6. Susan Vaughn, "Libraries Give Delegates a Taste of the Big Apple: Ready Answers on Short Notice," NYLA Bulletin 28:6 (1980): 6.

7. "Guidelines for Medical, Legal, and Business Responses at General Reference Desks," $R Q$ 31:4 (Summer 1992): 555 .

8. Diane G. Schwartz and Dottie Eakin, "Reference Service Standards, Performance Criteria and Evaluation," The Journal of Academic Librarianship 12:1 (1986): 6.

9. Marcia J. Myers, "The Accuracy of Telephone Reference Services in the Southeast: A Case for Quantitative Standards," in Library Effectiveness: A State of the Art, ed. by Neal K. Kaske and William G. Jones (Chicago: Library Administration and Management Association, 1980), 229.

10. Mary Lee Bundy, Amy Bridgman, and Laura Keltie, "Public Library Reference Service: Myth and Reality," Public Library Quarterly 3:3 (Fall 1982): 18.

11. Diane M. Brown, "Telephone Reference Questions: A Characterization by Subject, Answer Format, and Level of Complexity," RQ 24:3 (Spring 1985): 298.

12. Sharon L. Bostick, "Working for the Community: The Oakland County Experience," Technicalities 6 (February 1986): 9.

13. Eleanor Jo Rodger and Jane Goodwin, "To See Ourselves as Others See Us: A Cooperative, Do-It-Yourself Reference Accuracy Study," The Reference Librarian 18 (Summer 1987): 146.

14. "Massachusetts Studies Quality of Reference Service," Wilson Library Bulletin 62 (May 1988): 18.

15. Scott, 9.
16. Beth M. Paskoff, "Accuracy of Telephone Reference Service in Health Sciences Libraries," Bulletin of the Medical Library Association 79:2 (April 1991): 185.

17. Tammy Nickelson Dearie and Alice J. Perez, "Traditional Access to the Library via Telephone Service: A Case Study," Collection Management 17:1-2 (1992): 164.

18. Frank R. Allen and Rita H. Smith, "A Survey of Telephone Inquiries: Case Study and Operational Impact in an Academic Library Reference Department," $R Q 32$ (Spring 1993): 389.

19. Deborah C. Duke, “'Night Owl': Maryland's AfterHours Reference Service," Public Libraries 33 (May/June 1994): 48.

20. Regina Klein, "Who's Behind the Help Desk?," Database 11 (August 1988): 16.

21. Sharon M. West, "Information Delivery Strategies and the Rural Student," College and Research Libraries 53:6 (November 1992): 559.

22. Rosemarie Riechel, "The Telephone Patron and the Reference Interview: The Public Library Experience," The Reference Librarian 16 (Winter 1986): 83.

23. Rochelle Yates, A Librarian's Guide to Telephone Reference Service (Hamden, CT: Library Professional Publications, 1986), 58.

24. Bronwyn W. Parhad, "Managing Telephone Reference Services: Problems and Solutions, " The Reference Librarian 3 (Spring 1982): 122.

25. Daniel R. Smith, "Telephone Reference Training: Some Suggestions and Observations," Southeast Librarian 43 (Spring/Summer 1993): 8.

26. Yates, 58 .

27. Kathleen M. Neumann and Gerald D. Weeks, "Reference Materials in a Telephone Reference Service: A Model for Telereference," $R Q$ 20:4 (Summer 1981): 394.

28. James Joseph Small, "The Internet Gopher: A Reference Tool," The Reference Librarian nos. 41/42 (1994): 47.

29. J.S. Ottavaniani, "Archimedes: Analysis of a Hypercard Reference Tool," Collegeand Research Libraries 56 (March 1995): 171. 
30. James Powell, "Adventures with the World Wide Web: Creating a Hypertext Library Information System," Database 17 (February 1994): 62.

31. "Another Answer Line Service Added by Columbus and Franklin Co.," Library Journal 109 (1 October 1984): 1,794 .

32. Sever M. Bordeianu, "Portable Phone Enhances Reference Service," The Unabashed Librarian 77 (1990): 18.

33. Joseph A. Natale and James W. Galloway, "Remote Telephone Use in Reference Services," The Electronic Library 11:2 (April 1993): 106.

34. Cynthia Hess Nolan, "Voice Messaging Technology and Library Applications," Canadian Library Journal 49 (June 1992): 219.
35. Bruce Flanders, "Voice Mail: Enhancing Communications," Computers in Libraries 11 (February 1991): 29.

36. Susanne Bjorner, "Let Your Fingers Do the Searching: Call for the Fax," Online 17 (September 1993): 102.

37. Tina Roose, "Finding the Quickest, Easiest, and Cheapest Source of Information," Library Journal 114 (December 1989): 89.

38. Ken Kister, "Making the Connection: The Telephone as a Creative and Potent-but Underutilized-Instrument for Reference Service," The Reference Librarian 33 (1991): 109.

39. Ron Trice, "Locate Information-Toll Free," School Library Journal 32 (December 1985): 42.

40. "Toll Free Hotlines: A No-Cost, High Technology Reference Service," Public Libraries 19 (Spring 1980): 39.

\section{Now Avallable IN COMMUNITY INFORMATION MODULE MARC FORMAT}

\section{Directory of National Helplines}

(updated quarterly)

Directory of National Helplines is a specialized directory of social, economic, health, and environmental helplines for persons in need of support and advice. The helplines are sponsored by national organizations as well as less visible agencies that provide services to runaway children; work to prevent domestic violence; provide AIDS counseling and monitor related research; dispatch emergency response teams to handle toxic spills and other environmental emergencies; help provide enabling technologies to persons with physical disabilities; and more.

Directory of National Helplines also includes a section of selected TraveLines, providing access to a large number of travel services. Travelines provides access to agencies that send free information or provide free travel services for their respective areas of responsibility.

Directory of National Helplines covers toll-free public service numbers, e-mail addresses, Internet services, and selected fax lines.

For each helpline, Directory of National Helplines indicates: the hours it is available; the types of assistance provided; whether related resources (such as pamphlets) are available; and the sponsoring organization or agency. Library of Congress and other subject headings augment keyword access.

The electronic version of Directory of National Helplines is available from many vendors of online public access catalogs. Please contact Pierian Press for a current list and additional information:

The Pierian Press, Box 1808, Ann Arbor, Michigan 48106

Voice (800) 678-2435 = FAX (313) 434-6409

Directory of National Helplines in also available in print for $\$ 7.00$ (prepaid). The print version contains over 500 helpline listings and over 130 selected TraveL ines. The 1995 print version does not include e-mail addresses, Internet services, or fax lines. Quantity discounts are available. 